\title{
The Effectiveness of Interactive Patient Education on Adherence to Leprosy Medications in an Ambulatory Care Setting Indonesia: A Randomized Control Trial
}

\author{
Yayuk Nuryanti(i), Ruth Harriet Faidiban*(D), Hosiana Sombuk(D), Ivonne Junita Fabanjo(i), Niluh Gede Susantie(D), \\ Oktoviandi Sawaasemariay (D), Waode Suriani (i), Gidion Mansa (D)
}

Department of Nursing, Manokwari Poltekkes, Ministry of Health, Sorong, Indonesia

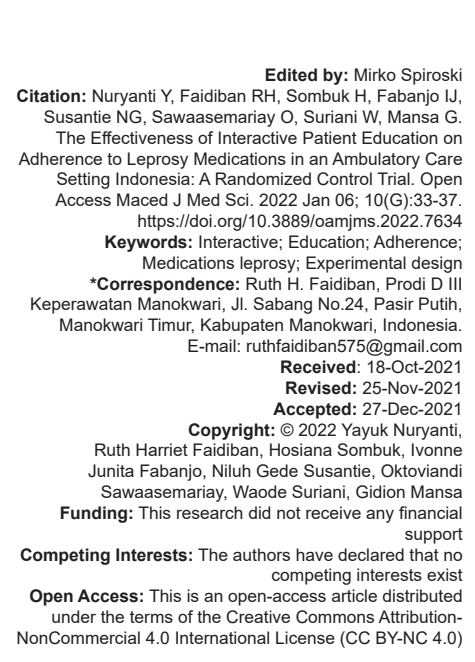

\section{Introduction}

Leprosy is a neglected tropical disease that annually causes irreversible physical disability in about 200000 people [1]. In 2020, almost 95\% of new leprosy cases will be diagnosed in 22 priority countries [2]. Adisproportionate number of leprosy cases occur among people living in low- and middle-income nations who are poor in terms of social and economic conditions. 4 In Indonesia, the country with the third-highest number of leprosy cases (8\%) 5 [3]. In Indonesia, the prevalence rate was 0.70 per 10,000 , and the annual rate was 6.08 per 100,000 [3]. In West Papua, there were about 640 new cases of leprosy, with the highest numbers in Teluk Wondama Regency (56), Manokwari Regency (24), and Sorong City (18) [4].

Patients with leprosy are categorized for therapeutic purposes based on the number of skin lesions [5], [6]. Defaulting from treatment refers to a person with leprosy who does not finish the entire course of multidrug therapy (MDT) despite numerous attempts by health care providers to assure the completion of treatment [5]. Treatment noncompliance remains a significant impediment to effective leprosy management and elimination in endemic areas [7], [8]. Interruptions and withdrawals from therapy may result in incomplete cures and re-infection of impacted communities. Delays in leprosy diagnosis and treatment can create irreparable physical disability, causing stigma and social disadvantage [9]. There has also been concern that patient noncompliance with MDT could contribute to medication resistance [8].

Poor treatment adherence has been linked to recurrence and the development of antibiotic resistance in leprosy patients [6]. Moreover, it has been related to decreased leprosy incidence and prevalence, both locally and globally (5-7,9-11). A potential explanation for poor treatment adherence is the lengthy duration of the MDT regimen, which lasts a year for patients with multibacillary leprosy and can be extended up to 3 years [8], [10], [11], [12], or even longer [13], [14]. Besides the lengthy duration of 
therapy, a variety of psychosocial, economic, medical and health-care-related factors, as well as individual characteristics, were identified to influence treatment adherence [15]. Preventing treatment default can be tackled in various ways, including through facilitybased measures to promote treatment adherence. Health education is an effective strategy that helps improve patients'medication adherence and selfmanagement skills [16]. Previous research has shown that structured health education programs improve treatment adherence in tuberculosis patients [17], but similar research in leprosy patients is lacking. Due to the COVID-19 pandemic, we expect e-health interventions to play a more significant role in promoting drug adherence [18]. We conducted a randomized controlled study to assess interactive patient education on adherence to leprosy medications in an ambulatory care setting in Indonesia.

\section{Methods}

\section{Study design}

A randomized controlled trial (RCT) was conducted between January and April 2021. The research was conducted at a public health center in West Papua, Indonesia. Leprosy was diagnosed in a total of 276 people. This RCT employed 1:1 randomization to allocate participants to one of two groups. The treatment group participated in an interactive patient education program, while the control group received routine care at the public health facility until data collection was complete. The control group then received the same intervention as the experimental group until the trial was completed. Before the intervention, a pretest measurement was taken. The post-test was done immediately following the conclusion of the intervention and 1 month later. Participants and researchers were both blinded, and no adverse events were observed during or following an intervention.

\section{Study population}

Eligibility criteria included: (a) Aged over 18 years old; (b) diagnosed with leprosy at least six months; (c) willing to participate in the intervention. Exclusion criteria were patients who did not experience mental or cognitive problems (confirmed by medical records) and had other comorbidities.

\section{Randomization}

The samples were chosen randomly (random. org). Each eligible participant was randomly assigned to either the intervention or the control group. A random number was generated for each matched pair and an unpaired participant to determine which treatment condition they would be placed in during the study.

\section{Intervention}

An interactive patient education program was developed based on literature review and expert discussion. There are three components to the interactive patient education program model: Motivation and psychological efficacy. The primary goal of the method is to empower patients with the knowledge and skills they need to enhance their health. This model has improved knowledge, abilities, and patient management of medical issues [19]. An interactive patient education program included four intervention steps: (1) Need assessment to determine the importance of adhering to physician-recommended medications and the associated health consequences; (2) problem-solving to increase self-efficacy; (3) educational participation to facilitate communication and self-esteem; and (4) process.

The intervention lasted 1 month, with four sessions each week lasting 60-90 min. Then, 3 weeks later, 30-min follow-up sessions were held through social media to remind participants of the intervention's content.

\section{Instruments}

A self-administered questionnaire collected personal data such as age, gender, education, marital status, employment, and social acceptability. The Morisky Medication Adherence Scale (MMAS-8) [20] was used to assess medication adherence. The MMAS-8 is a questionnaire comprised of eight questions meant to assess medication adherence. The first seven are yes/no questions, but the final one requires a response on a five-point Likert scale. Each statement receives one point based on the response. One point is awarded for each "NO" response in the first seven questions, except for question 5, which awards one point for each "YES" response. For item number 8, one point is awarded for "never/rarely," and zero points are awarded for "always." The total MMAS-8 score is calculated by adding the scores for each of the eight questions. The total score obtained is in the range of $0-8$.

\section{Procedure}

Ethical approval was obtained from the research ethics boards of affiliated universities before recruitment. Participants were provided with critical information in a letter that defined the research aims, criteria, and the voluntary nature of their involvement in the study. The Declaration of Helsinki made it explicit that participants had the right to withdraw from the study at any time and for any reason. The study's terms 
and conditions protected this right. This study relied on a participant's written informed consent. Researchers screened participants for eligibility, permission, and enrollment. Participants who met the inclusion criteria were randomly allocated to the intervention or control group. The intervention group was given an interactive patient education session once a week for 1 month. Due to the Pandemic of COVID-19, a research team produced an engaging patient education program using blended methods. Lectures, group discussions, and a question-and-answer session were all used to deliver the program. An interactive booklet imparts knowledge and skills regarding leprosy treatment and prevention, as well as increased ability, confidence, and skill and the capacity to improve communication abilities. During the second half of each session, group discussions and questions and answers were held on the topic-related drills. They get booklets at the end of each session. A telephone interviewer collected prospective data on adherence to leprosy therapy (baseline, immediately, and one month after intervention).

\section{Data analysis}

The Kolmogorov-Smirnov test was employed to determine whether or not the assumption of normality was correct. The independent sample t-test and chi-square test were performed to determine any demographic differences between the experimental and control groups. Intention-to-treat analyses were used to test the hypothesis that an interactive patient education program is more effective in improving adherence than a reference group. Participants in the intervention and control groups were compared using regression models that accounted for baseline levels of the dependent variable. The regressions with fixed effects were used to generate the estimates. All regressions had statistically significant standard errors. The difference-in-differences technique was used to evaluate the variances between T0 and T1 and T0 for the intervention versus control groups (DID). All analyses were conducted using SPSS version 23 .

\section{Results}

A total of 276 patients diagnosed with leprosy took part in the baseline data collection. At enrolment, approximately 200 participants agreed to join in this study (response rate $=72.5 \%$ ).

Table 1 presents descriptive statistics for baseline sociodemographic characteristics for intervention and control groups among participants in the analytical sample. There were no significant differences in baseline characteristics between the intervention and control groups.
Table 1: Comparison of baseline characteristics between intervention and control groups $(n=200)$

\begin{tabular}{llll}
\hline Variables & $\begin{array}{l}\text { Experimental, }(\mathrm{n}=100) \\
\%\end{array}$ & $\begin{array}{l}\text { Control, }(\mathrm{n}=100) \\
\%\end{array}$ & $\mathrm{p}$-value \\
\hline $\begin{array}{l}\text { Age in year (Mean } \pm \text { SD) } \\
\text { Gender }\end{array}$ & $41.56 \pm 0.37$ & $41.08 \pm 0.82$ & 0.56 \\
$\quad \begin{array}{l}\text { Male } \\
\quad \text { Female }\end{array}$ & $48(48.00)$ & $45(45.00)$ & 0.48 \\
$\begin{array}{l}\text { Marital status } \\
\quad \text { Single/divorce }\end{array}$ & $52(52.00)$ & $55(55.0)$ & \\
$\quad$ Married & $44(44.00)$ & $45(45.00)$ & 0.42 \\
$\begin{array}{l}\text { Working status } \\
\text { Yes }\end{array}$ & $55(55.00)$ & $55(55.50)$ & \\
$\quad$ No & $60(60.00)$ & $55(55.00)$ & 0.27 \\
$\begin{array}{l}\text { Education level } \\
\text { Below senior high school } \\
\quad \text { Above senior high school }\end{array}$ & $50(56(44.00)$ & $45(45.00)$ & \\
Social acceptability & $44.00)$ & $52(52.00)$ & 0.10 \\
$\quad$ Yes & $58(58.00)$ & $48(48.00)$ & \\
$\quad$ No & $42(42.00)$ & $55(55.00)$ & 0.11 \\
\hline
\end{tabular}

Table 2 provides the baseline and T1 and T2 means, by study group, among the analytical sample for the primary indicators of interest. In the intervention group, at baseline, respondents showed low levels of medications adherence, with an average score of 335 $(S D=1.05)$. Medication adherence levels increased at T2 as respondents in the intervention groups scored 6.22 (SD =1.53), and respondents in the control group scored $3.12(S D=1.45)$.

Table 2: Outcomes among sample by intervention and control groups

\begin{tabular}{lll}
\hline Variables & $\begin{array}{l}\text { Experimental, }(\mathrm{n}=225) \\
\text { Mean } \pm \text { SD }\end{array}$ & $\begin{array}{l}\text { Control, }(\mathrm{n}=220) \\
\text { Mean } \pm \text { SD }\end{array}$ \\
\hline Medication adherence & $3.35 \pm 1.05$ & \\
Baseline & $5.72 \pm 1.16$ & $3.17 \pm 1.01$ \\
T1 & $6.22 \pm 1.53$ & $3.98 \pm 1.33$ \\
T2 & & $3.12 \pm 1.45$ \\
\hline
\end{tabular}

Table 3 shows estimated difference-indifferences (DID) for intent-to-treat (ITT) results from linear regressions with level fixed effects. An interactive patient education program improved outcomes relative to the control at $\mathrm{T} 1$; medication adherence increased 0.11 (95\% Cl 0.01-0.25). At T2, improved outcomes relative to the control were observed in medication adherence (DID coefficient 0.31 (95\% CI 0.10-0.59).

Table 3: Estimated difference-in-differences (DID)

\begin{tabular}{lll}
\hline Variables & T1 & T2 \\
& DID coefficient $(95 \% \mathrm{Cl})$ & DID coefficient $(95 \% \mathrm{Cl})$ \\
\hline Medication adherence & $0.11^{\star}(0.01-0.25)$ & $0.31^{*}(0.10-0.59)$ \\
\hline${ }^{*} \mathrm{p}$-value $=0.011,{ }^{*} \mathrm{p}$-value $=0.001$ & &
\end{tabular}

\section{Discussion}

The purpose of this study was to determine the effect of an interactive patient education program on medication adherence in ambulatory care patients with leprosy. The research intervention was found to improve medication adherence significantly. It is important to us that our interactive patient education program considers the patient's view of the necessity of adhering to their prescription regimen and how 
effectively that knowledge is presented. Given the enormous economic burden that leprosy care could have on Indonesia shortly, incorporating this program into the healthcare delivery system, albeit with a significant increase in patient educator contact hours, should result in efficient and cost-effective care. More research is needed on the long-term advantages of interactive patient education programs in diverse age groups and larger patient cohorts.

Adherence was higher in the intervention group than in the control group [21]. The high prevalence in this study could be due to selection bias in a clinical study. A similar level of compliance to hormonal replacement therapy in postmenopausal women was found in another Danish clinical trial [22], which found that $86 \%$ of women adhered to the treatment. Adherence increased significantly in the intervention group compared to the control group in the current trial. Similar findings have been seen in other chronic disease medication trials. A group-based patient education program for people with type 2 diabetes reduced $\mathrm{HbA} 1 \mathrm{c}$ by $0.4 \%$, p 0.01 , 24 months after baseline [23]. Continually providing group information on leprosy disease care and treatment is required to promote medication adherence [24]. Few disease-specific educational programs have been evaluated in randomized trials; it is unknown which programs are the most successful or whether particular attitudes or tactics should be chosen. The present study took an interactive approach that emphasized an interactive education program and incorporated patients' daily lives and experiences. Following this, a recent Cochrane study concluded that significant innovations in increased adherence are more likely to arise when investigators collaborate across clinical disciplines and actively include patients in problem-solving [25].

In the present study, adherence was defined broadly to capture the whole range of medicationtaking behavior, which ranges from occasional nonadherence to persistent dose reductions, as well as dose increases or complete cessation of medication (non-adherence). The study's strength is that it focuses on patients' medicine intake (for leprosy); consequently, they were still considered adherent if patients changed their leprosy medication. Many studies analyze only one behavior (treatment versus no treatment), but patients often have several options. An individual may esteem one dosing regimen but choose not to employ it because a second regimen is more preferred [26], [27].

Several significant study limitations should be mentioned. The impact on medication adherence is not known to have a long-term effect. Longer follow-up studies could considerably increase confidence in an interactive patient education program. Whether this program applies to other demographics is unknown, but it appears to benefit low-income and minority communities. Updates and continuing evaluation are critical in current medication adherence. A descriptive curriculum with personal experience is required.

\section{Conclusions}

This study demonstrates that an interactive patient education program could effectively enhance medication adherence. Long-term changes in leprosy treatment could be influenced by efforts to improve regulations and the environment. This work makes a substantial contribution to developing an empowering and cost-effective way to deliver preventative interventions while also raising the voice of teenagers in health policy advocacy activities. Therefore, it is advised that health care professionals working with leprosy patients participate in the development of patient education programs and establish therapeutic partnerships with their patients.

\section{Data Availability}

The data that support the findings of this study are available on request from the corresponding author. The data are not publicly available due to containing information that could compromise the privacy of research participants.

\section{References}

1. World Health Organization. Guidelines for the Diagnosis, Treatment and Prevention of Leprosy. Geneva: World Health Organization; 2018. Available from: https://apps.who.int/ iris/bitstream/handle/10665/274127/9789290226383-eng. pdf?ua=1 [Last accessed on 2020 Mar 15].

2. Lazo-Porras M, Prutsky GJ, Barrionuevo P, Tapia JC Ugarte-Gil C, Ponce OJ, et al. World Health Organization (WHO) antibiotic regimen against other regimens for the treatment of leprosy: A systematic review and meta-analysis. BMC Infect Dis. $2020 ; 20(1): 1-14$.

3. Franco-Paredes C, de Oca Sanchez GM, White C. Global leprosy status in 2020: Still losing touch. Ann Acad Med Singap. 2020;49(1):1-2.

PMid:32200391

4. Kemenkes RI. Hapuskan Stigma dan Diskriminasi Terhadap Kusta. InfoDatin Pusat Data dan Informasi Kementrian Kesehatan RI. Jakarta: Kemenkes RI; 2018. p. 1-11.

5. Handog EB, Gabriel MTG, Co CC. Leprosy in the Philippines: A review. Int J Dermatol. 2011;50(5):573-81. https://doi. org/10.1111/j.1365-4632.2011.05044.x PMid:21506975

6. Chaptini C, Marshman G. Leprosy: A review on elimination, reducing the disease burden, and future research. Lepr Rev. 2015;86(4):307-15

PMid:26964426

7. Williams MC. How can adherence with multi-drug therapy in leprosy be improved? Lepr Rev. 2005;76(2):160-1.

PMid:16038249

8. Cooreman E, Gillini L, Pemmaraju V, Shridar M, Tisocki K, 
Ahmed J, et al. Guidelines for the diagnosis, treatment and prevention of leprosy. World Health Organ. 2018;1:106.

9. Smith CS, Aerts A, Saunderson P, Kawuma J, Kita E, Virmond M. Multidrug therapy for leprosy: A game changer on the path to elimination. Lancet Infect Dis. 2017;17(9):e293-7. https://doi. org/10.1016/S1473-3099(17)30418-8

10. Rodrigues LC, Lockwood DN. Leprosy now: Epidemiology, progress, challenges, and research gaps. Lancet Infect Dis. 2011;11(6):464-70. https://doi.org/10.1016/ S1473-3099(11)70006-8

PMid:21616456

11. Honrado ER, Tallo V, Balis AC, Chan GP, Cho SN. Noncompliance with the world health organization-multidrug therapy among leprosy patients in Cebu, Philippines: Its causes and implications on the leprosy control program. Dermatol Clin. 2008;26(2):221-9, vi. https://doi.org/10.1016/j. det.2007.11.007

PMid:18346553

12. World Health Organization. Each Blister Pack Contains Treatment for 4 Weeks, No. 50. Geneva: World Health Organization; 2020.

13. Pepito VC, Amit AM, Samontina RE, Abdon SJ, Fuentes DN, Saniel OP. Variations in the clinical management of multibacillary leprosy patients in selected hospitals in Metro Manila. Acta Med Philipp. 2018;52(3):268-76. https://doi.org/10.47895/amp. v52i3.409

14. Pepito VC, Amit AM, Samontina RE, Abdon SJ, Fuentes DN, Saniel OP. Patterns and determinants of treatment completion and default among newly diagnosed multibacillary leprosy patients:Aretrospective cohortstudy. Heliyon. 2021;7(6):e07279. https://doi.org/10.1016/j.heliyon.2021.e07279

PMid:34222685

15. Kumar A, Girdhar A, Chakma JK, Girdhar BK. WHO multidrug therapy for leprosy: Epidemiology of default in treatment in Agra district, Uttar Pradesh, India. Biomed Res Int. 2015;2015:705804. https://doi.org/10.1155/2015/705804

PMid:25705679

16. Delavar F, Pashaeypoor S, Negarandeh R. The effects of selfmanagement education tailored to health literacy on medication adherence and blood pressure control among elderly people with primary hypertension: A randomized controlled trial. Patient Educ Couns. 2020;103(2):336-42. https://doi.org/10.1016/j. pec.2019.08.028

PMid:31451361

17. Moodley N, Saimen A, Zakhura N, Motau D, Setswe G, Charalambous $\mathrm{S}$, et al. "They are inconveniencing us" - exploring how gaps in patient education and patient centred approaches interfere with TB treatment adherence: perspectives from patients and clinicians in the Free State Province, South Africa. BMC Public Health. 2020;20(1):454. https://doi.org/10.1186/ s12889-020-08562-3

\section{PMid:32252703}

18. Newman-Casey PA, Killeen OJ, Renner M, Robin AL, Lee P, Heisler M. Access to and experiences with, e-health technology among glaucoma patients and their relationship with medication adherence. Telemed J E Health. 2018;24(12):1026-35. https:// doi.org/10.1089/tmj.2017.0324

PMid:29683401

19. Keshvari M, Farashbandi FZ, Geraei E. Modelling influentia factors on customer loyalty in public libraries: A study of West Iran. Electron Libr. 2015;33(4):810-23. https://doi.org/10.1108/ EL-10-2013-0185

20. Morisky DE, Green LW, Levine DM. Concurrent and predictive validity of a self-reported measure of medication adherence. Med Care. 1986;24(1):67-74. https://doi. org/10.1097/00005650-198601000-00007

PMid:3945130

21. Wulff R, Abrahamsen B, Ejersted CA, Christensen PM, Brixen KT. Compliance with the treatment of osteoporosis with diphosphonates. A questionnaire among postmenopausal women. Ugeskr Laeger. 2004;166(1-2):49-53.

PMid:14752994

22. Eiken $\mathrm{P}$, Kolthoff $\mathrm{N}$. Compliance with 10 years oral hormona replacement therapy. Maturitas. 2002;41(2):81-6. https://doi. org/10.1016/s0378-5122(01)00246-8

PMid: 11836038

23. Sarkadi A, Rosenqvist U. Experience-based group education in Type 2 diabetes: A randomised controlled trial. Patient Educ Couns. 2004;53(3):291-8. https://doi.org/10.1016/j. pec.2003.10.009

PMid:15186866

24. Grosset KA, Grosset DG. Effect of educational intervention on medication timing in Parkinson's disease: a randomized controlled trial. BMC Neurol. 2007;7:20. https://doi. org/10.1186/1471-2377-7-20

PMid:17634109

25. Haynes RB, Ackloo E, Sahota N, McDonald HP, Yao X. Interventions for enhancing medication adherence. Cochrane database Syst Rev. 2008;2:CD000011. https://doi. org/10.1002/14651858.CD000011.pub4 PMid:25412402

26. Dowd R, Recker RR, Heaney RP. Study subjects and ordinary patients. Osteoporos Int 2000;11:533-6. https://doi.org/10.1007/ s001980070097

PMid:10982170

27. Barrett-Connor E, Wade S, Do T, Satram S, Stewart R, Gao G, et al. Treatment satisfaction and persistence among postmenopausal women on osteoporosis medications: 12-month results from POSSIBLE US (TM). Osteoporos Int. 2011;23(2):733-41. https://doi.org/10.1007/s00198-011-1620-3 PMid:21625886 